\title{
UNA MIRADA CASI DISTANTE
}

\author{
An almost distant gaze \\ Pablo Francescutti * \\ * Universidad Rey Juan Carlos (España) \\ luispablo.francescutti@urjc.es
}

Palabras clave

trayectoria biográfica

redes sociales

observación social

instituciones académicas

Keywords

biographical trajectory

social networks

social observation

academic institutions
Resumen

El inicio de una carrera de investigador en Argentina y su difícil continuación en España dan pie al autor para reflexionar sobre la importancia de las redes sociales en entornos académicos, y sobre la posición de orfandad a la que se ve destinado quien carezca de ellas en circunstancias de emigración. El relato de su trayectoria biográfica le sirve asimismo de hilo conductor para repasar las diferencias entre las instituciones universitarias de ambos países, señalar las inevitables transacciones sobre los objetos de estudio que se deben realizar entre las inclinaciones personales y las necesidades de adaptación, y concluir con una reivindicación de las ventajas de cara a la observación social derivadas de vivir a caballo de dos continentes.

\section{Abstract}

The beginnings of a research career in Argentina and its subsequent continuation in Spain are the basis of a reflection about how important social networks are when it comes to aspire to an academic position, and how marginal is the situation of the migrants who lack them. The author's biographical journey serves to underline differences between academic institutions of both countries, as well as point out the unavoidable adjustments relating to objects of study between personal leanings and adaptation needs, and finally, to defend the advantages in terms of sociological insight derived from living between two continents.

Francescutti, P., 2015, "Una mirada casi distante", en Papeles del CEIC, vol. 2015/1, no 119, CEIC (Centro de Estudios sobre la Identidad Colectiva), Universidad del País Vasco, http://dx.doi.org/10.1387/pceic.13016

Recibido: 6/2013; Aceptado: 10/2014

Termino un artículo para un periódico argentino y me pongo con la tarea pendiente: escribir una reflexión sobre mi condición de investigador sudamericano emigré. ¿Por dónde empezar? Quizás me ayude el texto que acabo de firmar: una reflexión acerca de la apropiación política por parte del gobierno de Cristina Fernández del personaje de historieta más célebre

\section{Papeles del CEIC}


de mi patria, El Eternauta. Debería facilitármela porque con el cómic arrancan mis pesquisas; primero, con un estudio de recepción aplicado a sus lectores durante la licenciatura; después con una tesina sobre EI Eternauta (Oesterheld y López, 1976) dirigida por Nicolás Rosa, chef de file de la semiótica criolla, con la que me gradué de antropólogo en la Universidad Nacional de Rosario el año de gracia de 1990.

¿Por qué tanto interés por la historieta? En parte el tópico me venía sugerido por la tradición académica; sus dispositivos de significación tenían fascinados a los semiólogos; además, su estatuto de género menor había atraído a los estudiosos de la comunicación, empeñados en reivindicar la cultura de masas despreciada por los letrados. Pero yo no era un semiólogo ni un aspirante a comunicólogo, sino un estudiante de antropología. ¿Qué tenía que ver el cómic con mi disciplina? No doy ninguna primicia si digo que, a mediados de los años ' 80 , la ciencia de la cultura se hallaba en aprietos: su objeto tradicional, las sociedades aborígenes, se desvanecía bajo los efectos aplastantes de la aculturación. Encima, en mi pago, epicentro argentino de la inmigración italiana, los indigenas brillaban por su ausencia. La antropología se veía obligada a reinventarse. La antropología educativa brindaba una salida; otra la ofrecía la antropología forense, de repentina notoriedad gracias a las exhumaciones de los desaparecidos; y yo atisbaba la mía en lo que se podría etiquetar de "antropología de la comunicación masiva". Hacer de EI Eternauta un tema de análisis encajaba en el plan. ¿Por qué esta pieza y no otra? A bocajarro respondería que porque se encuadraba en un género que me gustaba, la ciencia ficción. Además, la obra cumbre de la historieta criolla, de enorme difusión en sucesivas generaciones de lectores, daba para mucho: viajes en el tiempo, una invasión alienígena a Buenos Aires, una diégesis circular y la sangrienta victoria final obtenida por un líder guerrillero (iy esto último publicado bajo la dictadura de Videla!).

Con la tesina realicé mi primer acercamiento a la serie, mas el resultado no me dejó buen sabor de boca. Mi análisis me parecía superficial; había diseccionado el argumento sin ahondar en las cuestiones de fondo -el futuro en sus dos caras, apocalíptica y utópica, y el influjo de las representaciones del porvenir en el presente; cuestiones que tocaban 
asuntos familiares para cualquiera que hubiese participado de las luchas políticas de los años '60 y '70. En mi caso la familiaridad venía de mi militancia juvenil en una organización trotskista-. Al ingresar en sus filas, aparte de adoptar una visión de la Historia, de su curso y sus tareas, de sus héroes y sus villanos, uno se zambullía en un tiempo aparte. Dicho tempo, explicó Stephen Hanson (1997) en relación a la experiencia soviética, se vivía en una aceleración dictada por la creencia en el inminencia desenlace -el comunismo en la URSS; el evento revolucionario en nuestro caso-. Aunque la meta era crónicamente diferida, un frenesí de actividades nos mantenía en estado acelerado. El día nunca alcanzaba; las reuniones, las infinitas acciones proselitistas y organizativas se comían las pocas horas libres. El presente se sacrificaba al futuro redentor que muy pronto acaecería, si bien en el plano microsocial el tempo trepidante funcionaba como mecanismo compensador de la aceleración ausente en lo macrosocial: la revolución. Esa intuición temporal era común a todos los grupos revolucionarios, e incluso a la parte más activa de la juventud y la intelectualidad de otras latitudes.

Al abandonar la militancia me desacoplé de esa temporalidad y me planteé la cuestión en términos más críticos: ¿cómo y por qué el futuro había llegado a ejercer tal tiranía sobre el presente? Tal era el asunto que pretendía dilucidar a través del prisma de El Eternauta; pero no disponía de las herramientas analíticas y conceptuales para esa tarea, y la tesina quedó coja. Se dio la circunstancia de que mi familia, que en esas fechas había emigrado a Madrid, me animó a pasar una temporada a su lado y hacer el doctorado; luego, si quisiera, podría volver a Rosario y retomar la carrera iniciada como jefe de trabajos prácticos ad honorem (curiosa categoría de docentes que dan clases sin cobrar). En mi horizonte no figuraba vivir de la enseñanza; la mayoría de mis profesores se ganaban el pan en otros menesteres. Entonces yo fungía de escribiente en un juzgado de instrucción penal; había aprobado los exámenes estudiando El pensamiento salvaje y demás clásicos entre autos judiciales, y preveía que, una vez doctorado, seguiría sellando expedientes por la mañana y perorando sobre el kula frente a los somnolientos estudiantes del turno nocturno. 
Llegado a este punto siento la necesidad de alzar la guardia contra la ilusión biográfica mentada por Bourdieu (1997: 74-83) y negarme a reconstruir mi pasado como la trayectoria de una vocación que se despliega con firmeza hacia su destino. Nada de eso. Hubo perseverancia, muchos tanteos, dudas a montones, dispersión y desvíos provocados por las incertidumbres, los imperativos de supervivencia y las exigencias laborales. En mi mochila tenía disposiciones para ir en otra dirección si las cosas se hubieran barajado distinto. Lo más constante en mi itinerario fue el acatamiento del consejo de Nicolás Rosa: estudiar lo que a uno le apasiona y olvidarse de los tópicos que cotizan al alza en el mercado de las ideas, o sea casarse por amor y rechazar el matrimonio por conveniencia. Lo azaroso de mi derrotero se refleja en mi salida de Argentina. En nada se asemejaba a la success story de la joven promesa a quien sus mentores alientan a desarrollar su potencial en un centro de excelencia internacional y marcha pertrechada de becas y cartas de recomendación: yo era uno más en la estampida de graduados sin futuro, profesionales desesperados y personas arruinadas por la híperinflación que acabó con el gobierno de Alfonsín. En lugar del Grand Tour del intelectual latinoamericano tan bien descrito por David Viñas (1964), la mía era la escapada del pobretón. Es verdad que, aparte de la bancarrota nacional, en mi decisión de hacer las maletas incidian motivos más personales. Dice un adagio que los jóvenes disconformes consigo mismos estudian psicología; los disconformes con su sociedad, sociología; y los disconformes con sí mismos y con su sociedad, antropología. Este último era mi caso, con una diferencia: en vez de partir en busca de una tribu perdida me encaminé a la antigua metrópolis.

A los pocos meses de llegar a España, el huracán neoliberal arrasó lo que restaba del Estado benefactor argentino y se me quitaron las ganas de volver. Tuve un anticipo de lo que se venía encima poco antes de subir al avión: había telefoneado a la facultad por un trámite relativo al diploma y daba siempre ocupado; me personé en el decanato, golpeé la puerta y salió la secretaria: - Susana, parlanchina, ¡no parás de hablar!, le reproché. -No estaba hablando, Pablo, respondió, Nos cortaron la línea por impago, y el decano se va al bar de la esquina a llamar por teléfono público. 
Comparada con el escenario que dejaba a mis espaldas, la universidad española parecía Harvard - ibibliotecas equipadas! jaulas con calefacción! ¡Despachos y plazas de garaje para los profesores!-. Con todo, el encandilamiento inicial no me evitó los choques. En mi facultad de origen las clases se impartían en ronda, el mate circulando entre profesores y alumnos, siempre entre acaloradas polémicas; ahora me veía sentado frente a un estrado concebido para preservar las jerarquías, recibiendo discursos ex cátedra y percibiendo el fastidio de muchos docentes ante el menor cuestionamiento. No acabaron ahí los sacudones. Como buen sudaca, en mi equipaje traía la Teoría de la Dependencia junto con el anatema a la Teoría de la Modernización y a la colonizadora sociología funcionalista. Pero aterricé en Madrid justo para ver la caída de Ceausescu transmitida en vivo y en directo, y ese bagaje comenzó a disgregarse al contacto con los aires que soplaban.

Hubo más cimbronazos: mi creencia en una ciencia social europea única y canónica que comulga una misma koiné demostró ser un efecto óptico, una distorsión visual inducido por mi perspectiva periférica. Aprendí entonces que solo hay tradiciones nacionales blindadas por membranas herméticas que apenas dejan pasar unas pocas ideas foráneas tras el preceptivo proceso de filtro y traducción. Otra sorpresa: los estudiantes. Al contemplar el enorme parking de la facultad de Sociología repleto de coches en vez de las preceptivas bicicletas, tuve que admitir que mi concepción del estudiantado movilizado y de la autonomía universitaria como baluarte del progresismo frente a las tropelías de gobiernos despóticos y cipayos era un tipo ideal armado en base a una experiencia histórica acotada: la Reforma Universitaria latinoamericana (Portantiero, 1978), una gesta que ahora se me revelaba como una singularidad y no como el ethos común a quienes fatigan los claustros (de su excepcionalidad rinde testimonio la taquicardia de mis colegas españoles cuando les cuento que allende los mares hay jurados estudiantiles en los concursos docentes, introducidos para evitar chanchullos endogámicos). Y acto seguido constaté lo que resulta de la falta de un estudiantado activo y vigilante: el control total de la universidad por las camarillas clientelares. Agréguese a lo dicho mi desconcierto de latinoamericano afrancesado al ver cómo en la capital del reino torcían el gesto ante cualquier cosa que 
oliera a francés - jahora resultaba que Rosario estaba más cerca de París que Madrid! - . Sea como antídoto a la avasalladora influencia del vecino galo, sea por obra del esprit du temps, la academia española abrazaba los modelos empiristas de cuño anglosajón; y de ahí su desdén por lo que no se ajustara a la falsabilidad popperiana; desprecio que abarcaba a la tradición humanística local y a las ciencias sociales latinoamericanas, tachadas - con cierta razón-de ensayísticas. Descubrí al mismo tiempo la cercanía con el poder de la sociología hispánica, cuyos prohombres desempeñaban funciones de gobierno o asesoramiento - una novedad para quien venía de un lugar en donde los investigadores sociales eran perseguidos con saña por los que mandan-, lo que no quitaba que tuviera un núcleo duro de gran rigor intelectual.

La fortuna quiso que asistiese a un curso de verano en el que conocí a Ramón Ramos, el sociólogo que más ha hecho por introducir y asentar la teoría social del tiempo en la Península. No tardé en darme cuenta de que ese corpus era lo que me había faltado cuando analicé El Eternauta. Cambié el doctorado en antropología, controlado por los denostados funcionalistas, por el de sociología. Bajo la tutela de Ramos devoré la fascinante literatura sobre tiempos de trabajo, duración de las colas, profecías sociales, memoria colectiva, historia de los calendarios (Ramos, 1992), y la fascinación me sirvió de combustible para remar contra viento y marea.

Y tenía viento en contra. A poco de arribar a la madre patria comprendí que sin becas ni ayudas me iba a resultar muy difícil sacar el doctorado. Encima la homologación de estudios, hasta entonces automática, se había endurecido y tuve que examinarme para obtener el título de sociólogo. De golpe valoré la importancia crucial de las redes sociales en el éxito o fracaso de apuestas como la mía. De entrada podían determinar la obtención de becas predoctorales (en aquel entonces una red político/académica ligada el gobierno de Alfonsín acaparaba los contactos con las fundaciones europeas y el Instituto de Cultura Hispánica/AECID, y por alli yo no tenía nada que rascar). Ya en España me di cuenta de que carecía de la inserción que asegura el cursado de una carrera, a lo largo del cual el alumno con inquietudes se arrima a profesores influyentes, viendo 
allanado su acceso a becas, investigaciones, docencia, etc. En resumidas cuentas: rien de rien. Así las cosas, salí a buscar trabajo. Harto de hacer encuestas puerta a puerta, desempolvé el plan B que guardaba por si acaso mis objetivos se malograban. Con audacia o caradurez me personé en un periódico madrileño y pedí una oportunidad. Me la dieron, y por eso de que más cornás da el hambre me especialicé en un área informativa ajena a mis intereses y background: la divulgación científica. El cambio de chip no me disgustó y el periodismo me acaparó en cuerpo y casi en alma. Cuando podía me escapaba de la redacción para asistir a los cursos de doctorado en Somosaguas y luego retornaba a elaborar mis noticias. El plan A -la investigación social - se iba volviendo un hobby - o, como dijo alguien, una vanidad - al que dedicaba mis menguantes horas libres.

Corrieron los años. La prensa continuaba succionando mi tiempo vital y mis fuerzas. A trancas y barrancas reuní los créditos necesarios y encaré la tesis. Disponía ya del instrumental teórico con el que abordar la temporalidad moderna y su vertiente revolucionaria. El futuro, o mejor dicho los futuros, me seguían intrigando. ¿Cómo se construían, cómo variaban y, lo más interesante, cómo influían en el presente? Acentuaba su atractivo el hecho de que ese horizonte temporal fuera el menos analizado, ya que los estudiosos preferían centrarse en el presente social y el pasado -locus princeps del alto modernismo-. Propuse a Ramos que me dirigiera la tesis dedicada a la construcción social del futuro ("Ia construcción social" era el mantra académico en boga). Aceptó y puse manos a la obra. ¿Por dónde hincarle el diente? En parte por fidelidad a la ciencia ficción, en parte por pura cinefilia, escogí como corpus de análisis su expresión cinematográfica. De las miles de películas disponibles escogí las referidas a la energía atómica. Tenía razones para ello: en las representaciones del futuro es tangible el enorme impacto social, cultural y político de la liberación del poder nuclear, e igual ocurre en el imaginario científico del siglo XX. Con estas me hallaba familiarizado gracias a mi labor de divulgador. La tecnología nuclear y la resistencia social suscitada por ella eran tópicos candentes de la agenda mediática (desde 1984, regía en España una moratoria nuclear, una de las más sorprendentes tentativas de dar un frenazo a la aceleración tecnológica). Por añadidura, las utopías tecnocráticas constituian un ingrediente capital del ethos científico que los 
periodistas especializados reproducíamos con obediencia canina. La proximidad a la cultura atómica me ayudaba a interpretar las películas, y, en un movimiento circular, el examen de su entramado me obligaba a reconsiderar mis clichés cientificistas de matriz marxista-progresista y a sintonizar con la crítica de la tecnociencia alentada por el ecologismo y pensadores afines.

Hubo otro encuentro clave, esta vez con Jorge Lozano, el reputado semiólogo. Conocía su aplicación del análisis del discurso a la historiografía, una metodología que me vendría de perlas a la hora de analizar los enunciados fílmicos sobre la temporalidad. Aceptó ayudarme, y en la práctica, que no en los papeles, fungió de codirector de tesis, con lo cual se restableció mi vínculo con la semiótica cortado al salir de Argentina. Otro hecho providencial fue el cierre de la revista en la cual trabajaba. Al saber que me tocaba un año de seguro de desempleo fui el despedido más feliz: idispondría de un sucedáneo de beca para rematar la tesis! Quién diría que los caminos del saber pasaban por el INEM. A cambio de asistir a un curso de autoempleo (cómo abrir una mercería en un suburbio madrileño) consegui doce preciosos meses para dedicarme al estudio del tiempo.

Me encerré en un chalet de un olivar próximo a Toledo y avancé bastante, aunque no lo suficiente. Al agotarse el subsidio recibí la oferta laboral de un periódico que no me atreví a rechazar. Mi currículum periodístico engrosó un par de líneas y la tesis sufrió otro parón. Al cabo de un año, logré que en la redacción me asignaran al turno nocturno. De no mediar un terremoto en Jalisco o una catástrofe aérea en Kuala Lumpur, podía volver a mis películas mientras mis colegas montaban guardia jugando al mus. Noche tras noche, iba sacando adelante mi pesquisa sobre el futuro, a sabiendas de que cada paso me aproximaba a un horizonte cerrado a cal y canto, ya que un tapón generacional frenaba la incorporación de jóvenes doctores a la universidad. Barruntaba que la falta de becas e inserción institucional me había condenado a una vía muerta: no sería investigador en España ni en Argentina. Un par de hechos me ayudaron a combatir el desánimo: por un lado, me reconecté con mis compañeros de licenciatura, devenidos profesores de la universidad rosarina, quienes generosamente 
mitigaron mi orfandad académica invitándome a dar clases en su máster: por el otro, me enredé en otras redes, entre ellas una promovida desde la Universidad del País Vasco que buscaba articular a las nuevas hornadas de científicos sociales de ambos lados del charco de un modo distinto al habitual (léase tráfico de influencia, trueque de favores o caza de financiación). De la continuidad de la última rinde testimonio el monográfico al que pertenece este texto.

Por fin, mi director dio el visto bueno a mi manuscrito y convocó el tribunal. Mi felicidad era casi completa: había culminado la pesquisa iniciada una docena de años antes. Los futuros de El Eternauta ya no me eran opacos; a la vista estaban sus deudas con la ciencia ficción norteamericana y los milenarismos de la izquierda insurgente; sobre todo, había descubierto cómo la influencia del mañana se materializaba a través de un proceso de imitación. Parafraseando la máxima "la naturaleza imita al arte", podía afirmar que la sociedad contemporánea copia a la ciencia ficción valiéndose de sus imágenes, tramas y tropos como elementos persuasivos al servicio de anhelos, terrores y luchas de poder, que a la postre actúan como profecías suicidas o autocumplidas.

En breve sería doctor, ¿qué haría con mi carnet de sabio? La vida de periodista de día y sociólogo de noche no daba para más. Quería dedicarme a la investigación a tiempo completo, pero en las carreras de ciencias sociales había pocas vacantes y largas colas de meritorios esperando turno. La mayoría de mis compañeros de doctorado habían tirado la toalla o retornado a América Latina. Con ese estado de ánimo leí la tesis, sin saber que, como en un happy ending de Hollywood, al final me aguardaba la recompensa. A los postres del almuerzo con el tribunal, Lozano me informó que se había abierto una puerta. La creación de una nueva facultad de comunicación en Madrid y la buena acogida que me dispensó su decano Enric Saperas me permitieron regresar a la docencia.

Tras el paroxismo militante y el frenesí periodístico, me tocó ser atrapado por una aceleración desconocida. Atrás quedaban los sosegados ritmos del 
calendario académico que supe conocer en mis años de estudiante: ahora el profesor se veía compelido a una acumulación desenfrenada de currículum espoleada por la disyuntiva Publish or Perish ${ }^{1}$. En fin, el caso es que a matacaballo obtuve becas y ayudas para investigaciones, congresos y viajes, algunos con destino a Argentina. En mis visitas se me hicieron patentes los cambios habidos en el panorama intelectual autóctono. La desconexión del resto del mundo sufrida en los años '70 y '80 empezaba a remediarse. El prolongado imperio de la Escuela de Frankfurt —sustentado en el pesimismo de una intelligentsia arrinconada- cedía el cetro a paradigmas más recientes o incluso contemporáneos, un pasaje favorecido por la globalización, que obligaba a la producción autóctona a adaptarse a los parámetros teóricos, estilísticos y metodológicos anglosajones. Otros factores propiciaban el acercamiento entre los de dentro y los de fuera: la reinserción de Argentina en la división internacional del trabajo durante el gobierno de Carlos Menem, que facilitó los viajes formativos, intercambios e investigaciones conjuntas; y el giro iberoamericano de la política exterior española simbolizado en los fastos del Quinto Centenario. Hasta ese momento, el interés del profesorado hispano por Latinoamérica era escaso; más que asociarse a los parientes pobres del Sur le urgía engancharse a los centros punteros del Norte. La excepción la ponían los especialistas cuyos objetos de estudio remitian al subcontinente (qué duda cabe que para la americanística no hay nada mejor que América) y los catedráticos con cotos vedados en el Nuevo Mundo, fuente de invitaciones, honores y alumnos para sus posgrados. La situación dio un vuelco al llover el maná de las agencias de cooperación y de las empresas españolas: se multiplicaron las tesis sobre inmigración, relaciones bilaterales, etcétera; universidades y equipos de ambos lados del Atlántico salieron a la caza de contrapartes; los rectores se afanaron por firmar convenios $y$, cosa notable, por darles contenido (Oregioni y López, 2011). A mis compatriotas, en plena hambruna presupuestaria, esto

\footnotetext{
${ }^{1}$ La escasez de tiempo en la vida académica actual, la consecuencia de la intensificación del ritmo de producción intelectual, ha sido tratada por Heather Menzies (2007) en un artículo apropiadamente titulado No time to think.
} 
les cayó como una bendición; para mí fue la oportunidad de ejercer mi doble nacionalidad en lo académico. Con mis amigos sacamos adelante proyectos binacionales; y tuve la curiosa experiencia de ser invitado por la AECID a conferenciar en Montevideo y Rosario en calidad de experto español.

Esa situación, entre equívoca y cómica, me colocó frente a un problema del cual había oído quejarse a los escritores latinoamericanos radicados en España: ¿en qué idioma expresarse? ¿En español peninsular? ¿En castellano rioplatense, como hacía Julio Cortázar en París? ¿En un MidAtlantic Spanish que haga legible su obra a todos los hispanoparlantes, al precio de cierta alienación identitaria? Un reto similar se le plantea al investigador expatriado, no tanto de cara a sus medios expresivos ${ }^{2}$ como a su objeto de estudio. Del acierto con el que escoja este último dependerá su aceptación por parte de los contados lectores ante los que se juega el tipo: los evaluadores de las agencias de calidad ${ }^{3}$ y el público de las revistas académicas. Salvo que uno sea un americanista, no es fácil abrirse camino en España con la mente puesta en el otro continente. Más sensato parecía seguir los pasos de mi paisana Reyna Pastor, devenida una autoridad en el medioevo español. No era el único caso; conocía a latinoamericanos que, tras doctorarse, reorientaron sus afanes hacia asuntos potables para la academia de acogida. La otra opción entrañaba una esquizofrenia intelectual: desdoblarse y trabajar con un ojo puesto en los pares

\footnotetext{
${ }^{2}$ En lo concerniente a la lengua escrita, recibí un tratamiento de choque en mis primeros meses como periodista en Madrid. En ese periodo tomé conciencia de la gran diferencia entre el español peninsular y el castellano rioplatense, plagado de voces pasivas, construcciones tomadas del francés, gerundios, sujetos tácitos y multitud de extranjerismos -en especial traducciones literales de expresiones idiomáticas del inglés estadounidense. Hube de aprender a escribir de nuevo, ciñéndome férreamente a las construcciones Sujeto + Predicado + Complementos y evitando las oraciones largas.

${ }^{3}$ Un punto crítico del léxico a usar lo constituyen los términos "Latinoamérica" y "América Latina". Dichos vocablos, empleados por los habitantes de la América de habla castellana y portuguesa para autodenominarse, son resistidos por las instituciones oficiales de España, que ven en ellos un intento de diluir el legado español. Enseguida el solicitante de financiación aprenderá a sustituirlos por "Hispanoamérica", o "Iberoamérica" si el objeto de pesquisa incluye a Brasil.
} 
españoles y el otro en el país de origen. Elección peliaguda, típica del desarraigado incapaz de cambiar de acento o de cabeza.

Me decanté por un grado de esquizofrenia controlable: mantener, junto a los temas impuestos por la realidad circundante -el ecosistema mediático español- una línea centrada en la percepción del futuro como variable de la cultura argentina. Que la decisión valía la pena me lo confirmaron las calles de Buenos Aires, empapeladas de carteles con la cara del difunto presidente Néstor Kirchner superpuesta al rostro de El Eternauta. Al margen de las implicaciones políticas de esa operación de propaganda, el episodio del "Néstornauta" aportaba una prueba extraordinaria del mimetismo entre ciencia ficción y realidad social, pues la equiparación del líder peronista a un personaje de historieta superaba de lejos a la asociación de la política militar de Ronald Reagan a La Guerra de las Galaxias de George Lukas (Franklin, 1988). El futuro imaginado modelaba el presente y la historia copiaba a la historieta. Volviendo sobre mis pasos, retomé mi tesina de El Eternauta y la actualicé con reflexiones acerca de su encumbramiento a icono nacional (Francescutti, 2007). Lleva razón Salmon cuando dice que a los eruditos "nada les gusta tanto como que lo que estudian en soledad acceda de repente a la luz del día" (2008: 36): mi placer era doble porque, aparte de constatar que el tópico que motivó mi andadura sigue vivo y coleando, las inquietudes que me llevaron lejos del pago me reconectaban con mi comunidad originaria.

A la dicha de la reconexión se sumó el descubrimiento de los beneficios derivados de la distancia. El sistema de las ideas argentino - como cualquier otro, dicho sea de paso- vive relativamente cerrado sobre sí mismo, filtrando y bloqueando determinadas influencias externas $y$ traduciendo otras a sus códigos, conforme al proceso descrito por Lotman (1996: 26ss). Entre las influencias que su membrana liminal no dejaba pasar figura la teoría social del tiempo, posiblemente debido a su nulo encaje en una nación obsesionada con su pasado y con la Historia con mayúscula, en eterna introspección para descubrir cuándo se jodió la Argentina. Fue por esa razón que solo desde una posición exterior a esa semiosfera pude problematizar sus categorías temporales y adquirir las herramientas con las que explorarlas. En breve: el abordaje pleno de mi objeto se tornó

\section{Papeles del CEIC}


posible únicamente en un medio intelectual en donde esa reflexión no estuviese obturada. Por dar un ejemplo: sólo fuera de mi entorno cultural estuve en condiciones de ver una ausencia que de por sí constituye un dato relevante: la nula participación de Latinoamérica en la inmensa protesta antinuclear que sacudió a Norteamérica, África, Europa y Oceanía, uno de los movimientos sociales más impresionantes del siglo XX (Wittner, 1999). De la fenomenal movilización apenas tuve noticias en Argentina - punto de ciego de la observación-, lo que me llevó a pasar por alto las pistas sobre el larvado miedo atómico diseminadas en El Eternauta.

Los beneficios de la distancia son igualmente palpables cuando el punto ciego se halla en mi lugar de residencia. Lo comprobé a propósito de la teoría de la sociedad del riesgo de Ulrich Beck (2006), una de mis líneas de trabajo en Madrid. En su formulación inicial la teoría sostenía que la dinámica de los riesgos gobierna las sociedades post-industriales, mientras los países en desarrollo aún se hallan dominados por el conflicto entre las clases sociales. De allí se sigue el postulado de que la sensibilidad ambiental es privativa de la Segunda Modernidad, en tanto la periferia permanece aferrada a la mística de la industrialización, insensible a sus efectos adversos. Sin embargo, a poco que uno contemple el asunto desde un punto de vista latinoamericano verá que las luchas contra la minería contaminante, el conflicto de las papeleras en el río Uruguay, el combate contra la deforestación -entre un sinfín de protestas ambientalesponen en entredicho las posturas de Beck y obligan a repensar los riesgos con esquemas no evolucionistas ni eurocéntricos.

Recapitulando, la citada esquizofrenia depara una visión análoga a la mirada distante mentada por Levi-Strauss (1984), es decir, la perspectiva del etnólogo que le permite observar una cultura ajena como familiar y cercana, a la vez que induce una reflexión diferente y original sobre su medio al tornarlo lejano y extraño. Conservar la piel de meteco en el país adoptivo puede ayudar a mejorar la agudeza visual, sea a la hora de mirar España con ojos latinoamericanos, sea de contemplar Latinoamérica con ojos españoles. Cabe preguntarse, de todos modos, hasta qué punto semejante disposición se mantendrá conforme los años en el extranjero vayan empañando la visión. 
Con la reivindicación de la mirada "casi" distante - y digo "casi" porque la distancia nunca será demasiado grande entre quienes comparten lengua y códigos culturales - concluye mi mini-historia de vida, un intento de respuesta a la pregunta de Wright Mills (2003) por la relación entre biografia intelectual e historia. No he querido teorizar sobre la migración de los intelectuales -otros autores lo harán mucho mejor-, solo limitarme a dar un relato en primera persona de esos trasvases poblacionales y a identificar motivos particulares y coyunturas que quizá iluminen lo universal.

Es obvio que mi historia proseguirá después de estas páginas, pues me restan algunos años de actividad por delante, lapso en el que espero seguir haciendo equilibrio entre mis dos mundos. No se precisa una bola de cristal para avizorar que la consecución de ese objetivo se verá condicionada por el recorte de los fondos para la cooperación. Los escasos recursos se concentrarán en los proyectos más rentables en términos de imagen pública y en las áreas económicamente más apetitosas, con lo que nuestras cenicientas disciplinas persistirán en su austeridad habitual. Una cosa es segura: la internacionalización no tiene vuelta atrás, y esto vale también para los humildes flujos entre las ciencias sociales hispanoparlantes. Que los intercambios no decaigan también dependerá del impulso que los gobiernos de América Latina quieran darles, aunque mucho me temo que la colaboración discurrirá por los carriles actuales, modestos y voluntaristas, a presupuesto cero y gastos pagados por los implicados, más en la pauta del bottom-up que del top-down prescrito por las políticas científicas. A favor de la continuidad de los flujos juega la existencia, por vez primera en España, de un colectivo de investigadores latinoamericanos con posiciones académicas - muchos de ellos de mi camada, los arribados en los años '90-, cuyos contactos con sus países natales han configurado redes más o menos activas y estables; aunque me pregunto qué ocurrirá cuando dicho colectivo salga de escena por imperativo jubilatorio. Sería estupendo que las iniciativas de los cerebros fugados y sus socios locales repercutiesen en sus respectivas comunidades científicas -incluso si en su mayoría versasen de traducciones y aplicaciones de paradigmas importados de los países centrales-y el brain drain se convirtiera en un brain gain para ambas partes. Quedará a los 
historiadores del mañana inventariar el legado de esas migraciones ${ }^{4}$; a sus protagonistas solo nos resta perseverar en nuestros afanes, ya que no podemos ni queremos hacer otra cosa.

\section{BIBLIOGRAFÍA}

Beck, U., 2006, La sociedad del riesgo, Paidós Ibérica, Barcelona.

Bourdieu, P., 1997, Razones prácticas. Sobre la teoría de la acción, Anagrama, Barcelona.

Francescutti, P., 2007, "De vuelta al futuro con El Eternauta", Punto de Vista $\mathrm{n}^{\circ} 87, \mathrm{pp} .13-18$.

Franklin, H. B., 1988, War Stars. The Superweapon and the American Imagination, Oxford University Press, New York.

Hanson, S., 1997, Time and Revolution. Marxism and the Design of Soviet Institutions, University of North Carolina Press, Chapel Hill.

Lévi-Strauss, C., 1984, La mirada distante, Argos Vergara, Barcelona.

Lotman, I., 1996, La Semiosfera I. Semiótica de la cultura y del texto, Cátedra, Madrid.

Menzies, H., 2007, "No time to Think", Time $\in$ Society, $n^{\circ}$ 16, pp. 83-98.

Oesterheld, H. G. y López, S., 1976, El Eternauta, Ediciones Récord, Buenos Aires.

Oregioni, MP y Lopez, MP., 2011, "La gestión de la cooperación internacional en la Universidad argentina", Cuadernos del Cendes, $n^{\circ}$ 76, pp. 49-65.

Portantiero, J.C., 1978, Estudiantes y política en América Latina. El proceso de la reforma universitaria (1918-1938), FCE, México.

Ramos Torre, R., 1992, Tiempo y Sociedad, CSIC, Madrid.

Salmon, C., 2008, Storytelling. La máquina de fabricar historias y formatear mentes, Península, Barcelona.

4 El único caso estudiado del que tengo referencia concierne al legado de los psicólogos argentinos residentes en España durante los años '70 y '80 (Sarrible, 2000). Se trata de un intercambio definido por el exilio político; bastante diferente de las circunstancias referidas en el presente texto. 
Santamaría, E., 2006, "Migraciones y ciencias sociales: el caso de los científicos sociales latinoamericanos en España", REIS, $n^{\circ} 111$, pp. 271-288.

Sarrible, G., 2003, "Innovación social y migraciones: los argentinos en España", Scripta Nova, $n^{\circ}$ 69. Disponible en http://www.ub.es/geocrit/sn-69.htm

Viñas. D., 1964, Literatura y Realidad Política, Jorge Alvarez Editor, Buenos Aires.

Wittner, L., 1999, The Struggle Against the Bomb: Resisting the Bomb: A History of the World Nuclear Disarmament Movement, 1954-70, v. 2, Stanford University Press, Stanford.

Wright Mills, C., 2003, La imaginación sociológica, FCE, México. 